\title{
THE ABSENCE OF ANY EFFECT OF MATERNAL/ FETAL INCOMPATIBILITY AT THE H-2 AND H-3 LOCI ON PREGNANCY IN THE MOUSE
}

\author{
C. M. HETHERINGTON \\ Clinical Research Centre, Watford Road, \\ Harrow, Middlesex HA1 $3 U \mathcal{J}$
}

(Received 28th September 1972)

\begin{abstract}
Summary. In a series of matings between congenic strains of mice, differing at the $\mathrm{H}-2$ or $\mathrm{H}-3$ histocompatibility loci, decidual weight and lumbar and caudal lymph-node weight on the 7th day of pregnancy and placental and fetal weight and lumbar and caudal lymph-node weight on the 18th day of pregnancy were measured. There was no evidence that antigenic differences between mother and fetus at these loci affected any of these measurements. It was apparent, however, that there were significant differences between matings in decidual, placental and fetal weight, but not in lymph-node weight.
\end{abstract}

Except in matings between highly inbred strains of animals, the mammalian conceptus differs antigenically from its mother. A number of studies have been undertaken to determine whether the course of pregnancy is affected by the extent of these antigenic differences.

In the mouse, decidual weight (Hetherington, 1971) and placental weight (Billington, 1964) have been reported to be affected by the degree of antigenic dissimilarity between mother and conceptus while in the rat, maternal lymphnode weight is affected (Beer \& Billingham, 1971). Up to the present time, however, such studies have involved inbred strains of animals which not only differ at histocompatibility loci but also possess markedly different genetic backgrounds. It has been necessary, therefore, to estimate the significance of each of these two components in reaching a decision concerning the effect of antigenic difference on pregnancy. This has resulted in some differences of opinion about the significance of maternal/fetal incompatibility with respect to placental weight (see Clarke \& Hetherington, 1972).

If lymph-node weight, decidual weight and placental weight are affected by antigenic differences, these differences could be of considerable importance to the survival of the fetus. An understanding of the mechanisms involved might help to explain the success of the conceptus as a homograft.

In the present work, congenic resistant strains of mice were used, and a study was made of the effect of the $\mathrm{H}-2$ and the $\mathrm{H}-3$ histocompatibility loci. The $\mathrm{H}-2$ locus is the major histocompatibility locus of the mouse. The $\mathrm{H}-3$ antigen is stated to be expressed on the unimplanted blastocyst (Palm, Heyner \& Brinster, 
1971) and could, therefore, be of significance in the induction of the decidual cell reaction.

The three congenic strains B10/Sn $\left(\mathrm{H}-2^{\mathrm{b}}, \mathrm{H}-3^{\mathrm{a}}\right), \mathrm{B} 10 . \mathrm{A} / \mathrm{Sn}\left(\mathrm{H}-2^{\mathrm{a}}, \mathrm{H}-3^{\mathrm{a}}\right)$ and B10.Lp/Sn (H-2 $\left.{ }^{b}, \mathrm{H}-3^{\text {b }}\right)$ supplied by the Jackson Laboratory were used. Congenic resistant mice may be described as lines of mice identical with, or at least genetically very similar to, a standard inbred strain except for the substitution at one histocompatibility locus of a foreign allele (Green, 1968).

Female mice of the three strains were mated at 8 to 10 weeks of age. The day of finding the vaginal plug was taken to be the 1st day of pregnancy. Females of the B10/Sn strain were mated to males of the three strains. Females of the $\mathrm{B} 10 . \mathrm{A} / \mathrm{Sn}$ strain were mated to B10.A/Sn or B10/Sn males and B10.Lp/Sn females were mated to B10.Lp/Sn or B10/Sn males.

Lumbar and caudal lymph nodes were dissected out and weighed together on the 7 th or the 18th day of pregnancy. Decidual weight on the 7th day of pregnancy and placental and fetal weight on the 18th day of pregnancy were obtained as described previously (Hetherington, 1971).

Lymph-node weights within mothers of a given genotype were analysed by the Student $t$ test or by analyses of variance. Decidual weights were analysed by Duncan's multiple range test (Duncan, 1955). Placental and fetal weights were compared by the regressions of placental and fetal weights on litter size (Healey, McLaren \& Michie, 1960).

There were no significant differences in lymph-node weight within mothers of the same genotype on either the 7th or the 18th day of pregnancy (Table 1). Lymph-node weight on the 18th day of pregnancy was greater than on the 7 th day in all groups, but there were no significant differences in the extent of the increase between groups. An analysis of the regression of lymph-node weight on litter size indicated that although six of seven coefficients were positive, none was significant.

There were no significant differences in decidual weights in comparisons within mothers of the same genotype or between reciprocal crosses. Decidual weight in B10.Lp/Sn and B10.A/Sn mothers tended to be greater than in $\mathrm{B} 10 / \mathrm{Sn}$ mothers. The differences between the decidual weights from the isogeneic matings $\mathrm{B} 10 / \mathrm{Sn} \times \mathrm{B} 10 / \mathrm{Sn}$ and $\mathrm{B} 10 . \mathrm{A} / \mathrm{Sn} \times \mathrm{B} 10 . \mathrm{A} / \mathrm{Sn}$ were significant $(P<0.05)$. Decidual weight in between-strain crosses was intermediate between decidual weights of within-strain matings, except in the mating B10.Lp/Sn $\times$ B10/Sn.

The slopes of the regressions of placental weight on litter size did not differ significantly $(F=1.9$, d.f. $=6$ and 123). Placental weight in the isogeneic cross, $\mathrm{B} 10 / \mathrm{Sn} \times \mathrm{B} 10 / \mathrm{Sn}$, was significantly greater than placental weight in the two other isogeneic crosses $(P<0 \cdot 05)$, and significantly greater than in the interstrain cross, $\mathrm{B} 10 / \mathrm{Sn} \times \mathrm{B} 10 . \mathrm{A} / \mathrm{Sn}(P<0.01)$, but not significantly greater than placental weight in the cross, $\mathrm{B} 10 / \mathrm{Sn} \times \mathrm{B} 10 . \mathrm{Lp} / \mathrm{Sn}(F=2 \cdot 5$, d.f. 1 and 35). Reciprocal crosses did not differ significantly. Placental weight in the isogeneic mating, B10.A/Sn $\times$ B10.A/Sn, was significantly less than in the cross, B10.A/Sn $\times$ $\mathrm{B} 10 / \mathrm{Sn}(P<0.05)$, but there was no difference between the isogeneic mating, B10.Lp/Sn $\times$ B10.Lp/Sn, and the cross, B10.Lp/Sn $\times$ B10/Sn $(F=2 \cdot 4$, d.f. 1 and 39).

There were no significant differences between the slopes of the regressions of 


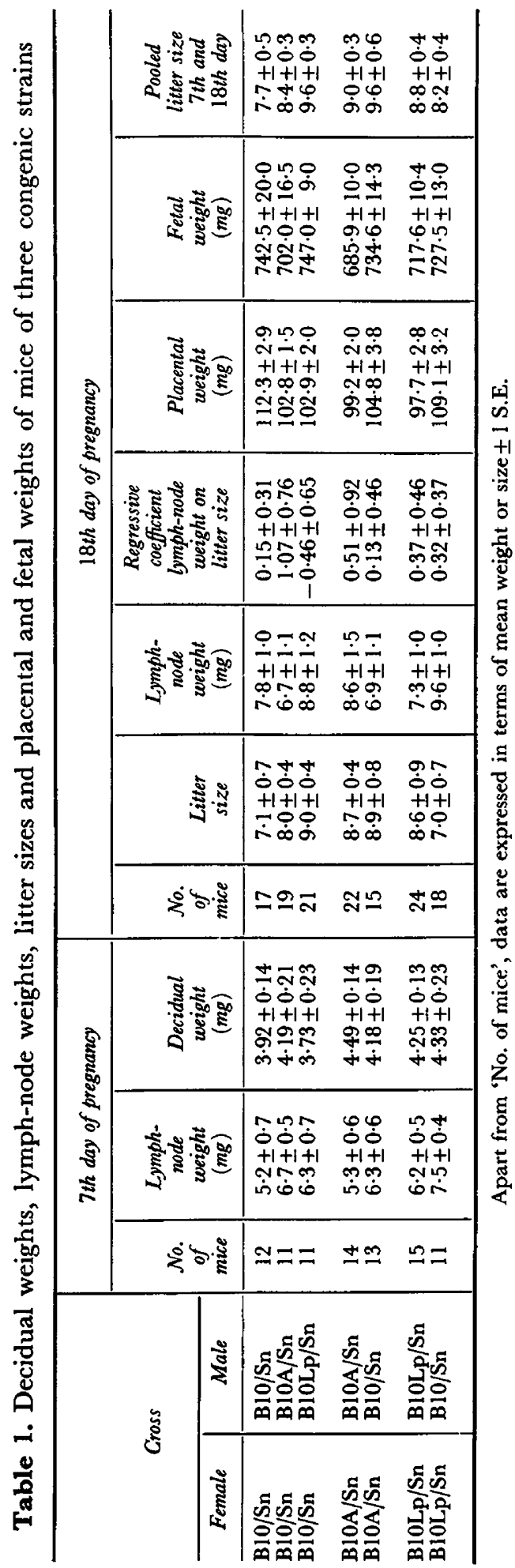


fetal weight on litter size $(F=2 \cdot 0$, d.f. $=6$ and 123). As with placental weight, fetal weight in the isogeneic mating, $\mathrm{B} 10 / \mathrm{Sn} \times \mathrm{B} 10 / \mathrm{Sn}$, was greater than in the two other isogeneic crosses and was significantly greater than in the mating, B10.A/Sn $\times$ B10.A/Sn $(P<0.001)$. Reciprocal crosses did not differ significantly from each other, but it was apparent that $\mathrm{B} 10 / \mathrm{Sn}$ females carried larger fetuses.

$\mathrm{B} 10 / \mathrm{Sn}$ and $\mathrm{B} 10 . \mathrm{A} / \mathrm{Sn}$ isogeneic litters were smaller than crossbred litters in females of the same strains, the differences in litter size between the two matings, $\mathrm{B} 10 / \mathrm{Sn} \times \mathrm{B} 10 / \mathrm{Sn}$ and $\mathrm{B} 10 / \mathrm{Sn} \times \mathrm{B} 10 . \mathrm{Lp} / \mathrm{Sn}$, being significant $(P<0 \cdot 05)$. Crossbred litters in B10.Lp/Sn mothers however tended to be slightly smaller than isogeneic litters, but the difference was not significant.

Maternal lymph-node weight has been reported to be greater in matings between strains of rats that differ antigenically than in matings within inbred strains (Beer \& Billingham, 1971). No evidence was found in this study to suggest that either an $\mathrm{H}-2^{\mathrm{a}} / \mathrm{H}-2^{\mathrm{b}}$ or an $\mathrm{H}-3^{\mathrm{a}} / \mathrm{H}-3^{\mathrm{b}}$ combination affects the weight of the lumbar and caudal lymph nodes in mice.

Similarly, there was no evidence that either decidual weight or placental weight was affected by incompatibility between mother and conceptus at the H-2 or H-3 locus as previously suggested by Hetherington (1971) and Billington (1964). Although significant differences between groups were found in decidual and placental weight, it was apparent that antigenic differences did not result consistently in a decrease in decidual weight or an increase in placental weight. The observations are in agreement with those of Finkel \& Lilly (1971) on placental weight in congenic mice.

In the majority of instances, decidual, placental and fetal weight in reciprocal crosses tended to be intermediate between those of the parental strains. One must conclude either that the $\mathrm{H}-2$ and $\mathrm{H}-3$ loci affect decidual, placental and fetal weight, but not in the way previously postulated, or that genetic variation between these strains is still sufficient to produce the observed result. The observation that placental weights in matings between congenic strains, where genetic variation is small, tended to be intermediate between the placental weights of the parental strains supports the hypothesis that the increase in placental weight associated with matings between conventional inbred strains is the result of hybrid vigour.

It has been suggested (Finkel \& Lilly, 1971) that there may be an increasing number of implantations per litter with increasing antigenic dissimilarity between mother and fetus. Some slight support for this hypothesis is provided from matings in which the mothers were either $\mathrm{B} 10 / \mathrm{Sn}$ or $\mathrm{B} 10 \mathrm{~A} / \mathrm{Sn}$. Litters resulting from $\mathrm{B} 10 / \mathrm{Sn} \times \mathrm{B} 10$. Lp/Sn matings were significantly larger than $\mathrm{B} 10 / \mathrm{Sn} \times \mathrm{B} 10 / \mathrm{Sn}$ litters $(P<0.05)$ while litter size in $\mathrm{B} 10 / \mathrm{Sn} \times \mathrm{B} 10 . \mathrm{A} / \mathrm{Sn}$ and $\mathrm{B} 10 \mathrm{~A} / \mathrm{Sn} \times \mathrm{B} 10 / \mathrm{Sn}$ matings tended to be greater than in the corresponding isogeneic mating, but the effect was not significant. In B10.Lp/Sn mothers, however, the litter size in isogeneic matings was the larger but the difference was not significant.

\section{REFERENCES}

BeER, A. E. \& Billingham, R. E. (1971) Immunobiology of mammalian reproduction. Adv. Immunol. 14, 1 . 
Billington, W. D. (1964) Influence of immunological dissimilarity of mothers and foetus on size of placenta in mice. Nature, Lond. 202, 317.

Glarke, A. G. \& Hetherington, G. M. (1972) Immunogenetic aspects of maternal/fetal relations. F. Reprod. Fert. Suppl. 15, 99.

Duncan, D. B. (1955) Multiple range and multiple F tests. Biometrics, 11, 1.

FinKeL, S. I. \& Lilly F. (1971) Influence of histocompatibility between mother and foetus on placenta size in mice. Nature, Lond. 234, 102.

GreEn, E. L. (Ed.) (1968) Handbook on genetically standardized Jax mice, 2nd edn. Bar Harbor Times Publishing Company, Bar Harbor, Maine.

Healey, M. J., McLaren, A. \& Michie, D. (1960) Foetal growth in the mouse. Proc. R. Soc. B, 153, 367.

Hetherington, C. M. (1971) The decidual cell reaction, placental weight, foetal weight and placental morphology in the mouse. F. Reprod. Fert. 25, 417.

Palm, J., Heyner S. \& Brinster, R. L. (1971) Differential immunofluorescence of fertilized mouse eggs with $\mathrm{H}-2$ and non-H-2 antibody. F. $\exp$. Med. 133, 1282. 